\section{A study on the functional properties of silk and polyester / lyocell mixed fabric}

\author{
Jeyakodi Moses Jeyaraj ${ }^{1}$, Mariappan Arumugam², \\ Vellingiri Kulandaiappan ${ }^{3}$
}

\author{
${ }^{1,2}$ Department of Applied Science, PSG College of Technology, Coimbatore 641004 \\ e-mail: jj_moses2k2@yahoo.co.in,marips_psg@yahoo.com \\ ${ }^{3}$ Department of Fashion Technology, PSG College of Technology, Coimbatore 641004, India \\ e-mail: rkvgiri@yahoo.com
}

\begin{abstract}
Silk is one of the valuable fibers in textile industry. It is used for delicate applications in many areas such as sarees, suitings, curtains and luxurious interiors. To diversify the properties and usages silk is mixed with polyester and lyocell. The fabric is dyed with natural dyes (kum kum, indigo, barberry) as well as synthetic dyes (reactive dye $(\mathrm{H})$, reactive dye $(\mathrm{M})$ and sulphur dye). This mixed fabric is compared with $100 \%$ silk for some of the basic properties like absorbency, water retention, wicking, water vapour permeability, air permeability, $\mathrm{K} / \mathrm{S}$ values, colour fastness and antimicrobial property. The silk mixed fabric gives the appreciable results with the $100 \%$ silk fabric.
\end{abstract}

Key words: Silk, lyocell, wicking, air permeability, antimicrobial

\section{INTRODUCTION}

Silk is a natural fibrous polymer consisting of amino acids. Silk fibers consist of $97 \%$ protein - fibroin, a filamentous protein (approximately 75\%) and sericin, a non-filamentous protein (nearly 25\%). Fibroin forms the inner layer or the core of the fibers, which is insoluble in hot water. It is having the chemical formulae C15H26N5O6. The sericin, which forms the outer layer, is a form of gum having the chemical formulae C15H23N5O6 [1, 2]. Unlike all other natural organic fibers like cotton, flax \& wool, silk does not have a cellular structure. The smoothness and translucence shown by the degummed silk is related to its different extents of surface reflections, internal transmitted light, internal reflected light and diffused light. It is highly hygroscopic, elastic, strong and gives good warmth and excellent drapeability [3, 4,5]. Silkfabricis famous for its soft handle, gloss, fineness, higher strength, high wearing comfort, appearance and other desirable aesthetics used for luxurious fashionable apparel, interior decorations. Hence, silk is rightly called "Queen" of textile fibers $[6,7,8]$.

Lyocell fibers may be defined as cellulosic fibers that are produced by regenerating cellulose into fiber form out of a solution in N-methylmorpholine-N-oxide (NMMO) [9]. Solvent spun lyocell fibers consist of crystalline cellulose-II and amorphous cellulose, and have a higher degree of crystallinity (80\%) in comparison with other regenerated cellulosic fibers, such as modal (49\%) and viscose (41\%) [10].The lyocell fibers, like other cellulosics, are moisture absorbent and biodegradable. They have a dry strength higher than other cellulosics and approaching that of polyester. They also retain $85 \%$ of their strength when wet. Under certain conditions lyocell fibers fibrillate which enables fabrics to be developed with interesting aesthetics. Non- fibrillating versions are also available. Lyocell fibers are mostly used for apparel fabrics, especially outerwear, but it has been shown that, due to the fibrillating property some very interesting nonwoven fabrics can be made as well [11]. Poly(ethylene terephthalate) fiber is widely used in production of garments because of their low production cost and good fiber properties such as mechanical strength, high stability against heat and chemicals and wash and wear properties [12]. Fabrics woven or knitted from polyester thread or yarn are used extensively in apparel and home furnishings, from shirts and pants to jackets and hats, bed sheets, blankets, upholstered furniture and computer mouse mats. Polyester fabrics can provide specific advantages over natural fabrics, such as improved wrinkle resistance, durability and high color retention [13]. As a result, polyester fibers are sometimes spun together with natural fibers to produce a cloth with blended properties [14]. The present study focused on the development of silk mixed fabric (silk (warp)and lyocell \& polyester (weft)). 
The fabrics were dyed using natural dyes (indigo, kum kum \& barberry) and synthetic dyes (reactive (M), reactive $(\mathrm{H})$ \& sulphur). The use of natural dyes on textile material has become very much popular throughout the world due to its eco-friendliness, ancient heritage and aesthetic approach. Since 1990, many researchers have been making enormous efforts to search new sources and different methods of applications with natural dyes [15]. For instance, natural kum kum powder, is traditionally made by mixing turmeric (Curcuma longa) collected from the rhizomes and lime. The dyed fabrics were subjected to different tests such as absorbency, water retention, wicking, water vapour permeability, air permeability, K/S values, colour fastness and antimicrobial property.

The results obtained are in appreciable manner particularly for sarees relevant with $100 \%$ silk.

\section{MATERIALS AND METHODS}

\subsection{Materials}

The two types of fabrics (1. 100\% silk (both warp \& weft) and 2. Silk (warp 100\%) and 50\% lyocell and 50\% polyester (weft) mixed fabrics) were used as mentioned in the following Table 1.

Tabela 1: Fabric details

\begin{tabular}{|c|c|c|c|}
\hline S. No. & Parameters & $\mathbf{1 0 0 \%}$ Silk & $\mathbf{5 0 \%}$ Silk+ (25\% polyester and 25\% lyocell) \\
\hline 1 & Warp Count & $2 / 80^{\text {s }}$ & Silk : 2/80 \\
\hline 2 & Weft Count & $2 / 80 s$ & Polyester and Lyocell (50: 50) : 2/80s \\
\hline 3 & Ends / Inch & 100 & 100 \\
\hline 4 & Picks / Inch & 60 & 68 \\
\hline 5 & GSM & 95 & 101 \\
\hline 6 & Cloth Width (Inch) & 44 & 44 \\
\hline
\end{tabular}

Natural dyes (kum kum, indigo, barberry) and synthetic dyes (reactive dye (M), reactive dye (H) and sulphur dye) used were in the commercial grade. The chemicals and auxiliaries mentioned elsewhere for this study were in AR grade

\subsection{Methods}

\subsubsection{Pretreatment on silk and its mixed fabric}

The above mentioned (2.1) materials were treated with 10 gpl hydrochloric acid for 60 minutes in a suitable separate baths with material to liquor ratio $1: 30$ at $30^{\circ} \mathrm{C}$ to get rid of the substrates added during weaving.

\subsubsection{Dyeing of silk and its mixed fabric}

The silk and its mixed fabric were dyed with natural (10 gpl, material to liquor ration, $1: 30$, temperature $95 \mathrm{oC}$, and time 2 hours) (indigo, kum kum \& barberry) and synthetic ( $2 \%$ on weight of fabric, material to liquor ratio $1: 20$, temperature $950 \mathrm{C}$, and time 2 hours) (reactive dye $(\mathrm{M})$, reactive dye $(\mathrm{H})$ and sulphur dye) dyes as per the established technique. The dyed samples were washed, soaped and dried [16, 17].

\subsubsection{Absorbency of silk and its mixed fabric}

Absorbency is the time taken for a water drop to penetrate into the textile material. The wettability of silk and its mixed fabric was determined as per AATCC test method 79-2010. [18].

\subsubsection{Water retention in silk and its mixed fabric}

Water retaining capacity of silk and its mixed fabric was measured by standard AATCC 21-1978 test method [19]. Absorptive capacity provides a measure of the amount of liquid held within a test specimen after specified times of immersion and drainage. The fabric samples were left immersed in water for twenty minutes. The 
samples were removed from water and allowed to drain for 10 seconds prior to weighing. The water absorptive capacity or water retention is given as percentage of the original mass of the fabric sample.

Water retention $=\underline{(\mathrm{B}-\mathrm{A}) \times 100}$

A

Where, $A=$ fabric weight before immersion (g)

and $\mathrm{B}=$ fabric weight after immersion (g)

\subsubsection{Wicking behaviour of silk and its mixed fabric}

The wicking height of the silk and its mixed fabric was determined [20]. Fabric samples measuring $10 \mathrm{~cm} \mathrm{X}$ $2.5 \mathrm{~cm}$ were taken. Each of the sample pieces was clamped to a scale and held at a position such that the tip of the sample just touched the water taken in a beaker. 1\% reactive dye (Reactive Red M8B, CI No.: Reactive Red 11) was added for tracking the movement of water. The height of water reached after five minutes was measured [21].

\subsubsection{Water vapour permeability of silk and its mixed fabric}

Water vapour permeability (WVP) is the speed or rate at which moisture vapor moves through a fabric. The ASTM E96-2000, moisture vapor test (open cup test) was used for measuring the WVP rate of the silk and its mixed fabric [22]. The ASTM E96 test is used for measuring the water vapour permeability which is the speed or rate at which the water vapor moves through a fabric.The rate of water vapor that passes through the fabric was determined by reduction in the height of water in the cup. Water was poured into cups upto $6 \mathrm{~cm}$ from base level. The cups were marked for every $0.5 \mathrm{~mm}$. The fabric samples were placed tightly on top of the cups where the water, the air above the water, and the room environment were at the same temperature and pressure.

After 48 hours the level of water decreased in the cups and the reduction in height of water was noted down.The moisture vapor transfer rate is the difference between the initial height of water and the actual height of water in the cups.The water vapor transport properties of textile materials are of considerable importance in determining the comfort properties of clothing systems. Water vapor transport through porous textiles may occur due to both diffusion (driven by vapor concentration differences) and convection (driven by gas pressure differences).

\subsubsection{Air Permeability of silk and its mixed fabric}

ASTM-D737-2012 method was used for measuring the air permeability of silk fabrics. This test gave the rate of airflow through a material under a differential pressure between the two faces of a fabric [23]. Air permeability is the rate of air flow passing perpendicularly through a known area under a prescribed air pressure differential between the two surfaces of a material. Air permeability is an important factor in the performance of textile materials such as gas filters, fabrics for air bags, clothing, mosquito netting, parachutes, sails, tent age and vacuum cleaners. Air permeability also can be used to provide an indication of the breathability of weather resistant and rain proof fabrics, or of coated fabrics in general, and to detect changes during the manufacturing process.Air permeability test gives the rate of airflow through a material under a differential pressure between the two faces of a fabric. It is expressed as the quantity of air in cubic centimeter passing per second through a square centimeter of the fabric.

\subsubsection{Measurement of $\mathrm{K} / \mathrm{S}$ value on dyed silk and its mixed fabric}

Colour intensities of the dyed silk and its mixed fabric were measured using spectrophotometer (model: Premier colour scan ss $5000 \mathrm{~A}$ ) within the range of $400-700 \mathrm{~nm}$. Reflectance values were measured and the relative colour strength (K/S) was calculated using Kubelka Munk equation [24] (K/S) defines a relationship between spectral reflectance $(R)$ of sample and its absorption $(K)$ and scattering $(S)$ characteristics. $K / S=\left\{(1-R)^{2} / 2 R\right\}$.

\subsubsection{Wash fastness on dyed silk and its mixed fabric}

The wash fastness of the dyed silk and its mixed fabric was determined by IS 764-test 3-1979 method [25].

The fabrics $(10 \times 4 \mathrm{~cm})$ were sewed along all four edges with same size of multi-fiber fabric. The composite specimen was washed at $60^{\circ} \mathrm{C}$ for 30 minutes using detergent solution $5 \mathrm{~g} / \mathrm{l}$ maintaining fabric to liquor ratio at 1: 50. The change in colour of the specimen and staining of the adjacent fabric were assessed by grey 
scale. The results were assessed in ratings from grade 1 (much altered) to grade 5 (unaltered) for change in colour of the specimen. The staining of the adjacent fabric was assessed in raings from grade 1 (much staining) to grade 5 (no staining).

\subsubsection{Light fastness on dyed silk and its mixed fabric}

The light fastness of the dyed silk and its mixed fabric was determined by AATCC test method 16E-2004 [26]. These dyed fabrics were exposed separately for 10 hours under artificial light source- xenon arc lamp.

\subsubsection{Fastness to rubbing on dyed silk and its mixed fabric}

Colour fastness to crocking was determined by AATCC test method 8-2007 [27]. AATCC standardized crockmeter was used to determine the rubbing fastness of dyed fabrics under wet and dry conditions to assess the staining property.

\subsubsection{Antibacterial property of dyed silk and its mixed fabric}

The antibacterial activity on the dyed fabric samples was assessed qualitatively according to the AATCC test method 147-2004 by the parallel streak method [28].

\section{RESULTS}

\subsection{Absorbency of silk and its mixed fabric}

The values of the absorbency of $100 \%$ silk and its mixed fabric dyed with indigo, kum kum, barberry, reactive dye $(\mathrm{M})$, reactive dye $(\mathrm{H})$ and sulphur dye are given in the Table 2.

Table 2: Absorbency of silk and its mixed fabric

\begin{tabular}{|c|c|c|c|}
\hline \multirow[b]{2}{*}{ S. No. } & \multirow[b]{2}{*}{ Dyes } & \multicolumn{2}{|c|}{ Drop Absorbency (Seconds) } \\
\hline & & $\begin{array}{c}100 \% \\
\text { Silk }\end{array}$ & $\begin{array}{c}50 \% \text { Silk+ (25\% polyester and } \\
25 \% \text { lyocell) }\end{array}$ \\
\hline 1 & Indigo & 26.1 & 15.2 \\
\hline 2 & Kum kum & 25.1 & 14.7 \\
\hline 3 & Barberry & 25.3 & 14.9 \\
\hline 4 & Reactive (M) & 24.9 & 13.8 \\
\hline 5 & Reactive dye $(\mathrm{H})$ & 24.7 & 13.5 \\
\hline 6 & Sulphur dye & 26.7 & 15.9 \\
\hline & Mean & 25.47 & 14.67 \\
\hline & Standard Deviation & 0.7737 & 0.8914 \\
\hline & Variance & 0.5987 & 0.7947 \\
\hline
\end{tabular}

\subsection{Water retention in silk and its mixed fabric}

The data of the water retention of silk and its mixed fabric are given in Table 3. 
Table 3: Water retention in silk and its mixed fabric

\begin{tabular}{|c|c|c|c|}
\hline \multirow{2}{*}{ S. No. } & \multirow{2}{*}{ Dyes } & \multicolumn{2}{|c|}{ Water retention (\%) } \\
\cline { 2 - 4 } & Indigo & $\begin{array}{c}\mathbf{1 0 0 \%} \\
\text { Silk }\end{array}$ & $\begin{array}{c}\text { 50\% Silk+ (25\% polyester } \\
\text { and 25\% lyocell) }\end{array}$ \\
\hline 1 & Kum kum & 318 & 345 \\
\hline 2 & Barberry & 321 & 348 \\
\hline 3 & Reactive (M) & 323 & 347 \\
\hline 4 & Reactive dye (H) & 324 & 349 \\
\hline 5 & Sulphur dye & 317 & 343 \\
\hline 6 & Mean & 320.5 & 347.17 \\
\hline & Standard Deviation & 2.74 & 2.86 \\
\hline & Variance & 7.5 & 8.17 \\
\hline
\end{tabular}

\subsection{Wicking behaviour of silk and its mixed fabric}

The values of the wicking behaviour of silk and its mixed fabric dyed with indigo, kum kum, barberry, reactive dye $(\mathrm{M})$, reactive dye $(\mathrm{H})$ and sulphur dye are given in Table 4.

Table 4: Wicking behaviour of silk and its mixed fabric

\begin{tabular}{|c|c|c|c|}
\hline \multirow[b]{2}{*}{ S. No. } & \multirow[b]{2}{*}{ Dyes } & \multicolumn{2}{|c|}{ Wicking (cm) [for 60 minutes] } \\
\hline & & $\begin{array}{c}100 \% \\
\text { Silk }\end{array}$ & $\begin{array}{l}50 \% \text { Silk+ (25\% polyester } \\
\text { and } 25 \% \text { lyocell })\end{array}$ \\
\hline 1 & Indigo & 13.7 & 15.2 \\
\hline 2 & Kum kum & 13.9 & 15.5 \\
\hline 3 & Barberry & 13.8 & 15.3 \\
\hline 4 & Reactive (M) & 14.0 & 15.6 \\
\hline 5 & Reactive dye (H) & 14.1 & 15.8 \\
\hline 6 & Sulphur dye & 13.6 & 15.1 \\
\hline & Tean & 13.85 & 15.42 \\
\hline & Deviation & 0.1871 & 0.2639 \\
\hline & iance & 0.035 & 0.0697 \\
\hline
\end{tabular}

\subsection{Water vapour permeability of silk and its mixed fabric}

The data of water vapour permeability of silk and its mixed fabric dyed with indigo, kum kum, barberry, reactive dye $(\mathrm{M})$, reactive dye $(\mathrm{H})$ and sulphur dye are given in the Table 5. 
Table 5: Water vapour permeability of silk and its mixed fabric

\begin{tabular}{|c|c|c|c|}
\hline \multirow[b]{2}{*}{ S. No. } & \multirow[b]{2}{*}{ Dyes } & \multicolumn{2}{|c|}{ Water Vapour permeability (g/m²/day) } \\
\hline & & $\begin{array}{c}100 \% \\
\text { Silk }\end{array}$ & $\begin{array}{c}50 \% \text { Silk+ (25\% polyester and } \\
25 \% \text { lyocell })\end{array}$ \\
\hline 1 & Indigo & 1838 & 2031 \\
\hline 2 & Kum kum & 1843 & 2036 \\
\hline 3 & Barberry & 1840 & 2034 \\
\hline 4 & Reactive (M) & 1846 & .2038 \\
\hline 5 & Reactive dye (H) & 1847 & 2040 \\
\hline 6 & Sulphur dye & 1835 & 2029 \\
\hline & Gean & 1841.5 & 2034.67 \\
\hline & Deviation & 4.68 & 4.18 \\
\hline & riance & 21.9 & 17.47 \\
\hline
\end{tabular}

\subsection{Air Permeabilityof silk and its mixed fabric}

The values of air permeability of silk and its mixed fabric dyed with indigo, kum kum, barberry, reactive dye $(\mathrm{M})$, reactive dye $(\mathrm{H})$ and sulphur dye are given in the Table 6.

Table 6: Air permeability of silk and its mixed fabric

\begin{tabular}{|c|c|c|c|}
\hline \multirow{2}{*}{ S. No. } & Dyes & \multicolumn{2}{|c|}{ Air Permeability l/min } \\
\cline { 3 - 4 } & Silk & $\begin{array}{c}\mathbf{1 0 0 \%} \text { Silk+ (25\% polyester and } \\
\mathbf{2 5 \%} \text { lyocell) }\end{array}$ \\
\hline 1 & Indigo & 55.8 & 110.2 \\
\hline 2 & Kum kum & 54.1 & 109.8 \\
\hline 3 & Barberry & 55.8 & 108.8 \\
\hline 4 & Reactive (M) & 55.1 & 108.3 \\
\hline 5 & Reactive dye (H) & 54.2 & 109.5 \\
\hline 6 & Sulphur dye & 55.0 & 109.3 \\
\hline \multicolumn{2}{|c|}{ Standard Deviation } & 55.0 & 109.32 \\
\hline \multicolumn{2}{|c|}{ Variance } & 0.7403 & 0.6853 \\
\hline
\end{tabular}

\subsection{K/S values of dyed silk and its mixed fabric}

The colorimetric data of indigo, kum kum, barberry, reactive dye (M), reactive dye $(\mathrm{H})$ and sulphur dyes applied on silk and its mixed fabric are given in Table 7. 
Table 7: K/S values of dyed of silk and its mixed fabric.

\begin{tabular}{|c|c|c|c|c|c|c|c|c|c|c|c|c|c|}
\hline \multirow{3}{*}{$\begin{array}{l}\text { S. } \\
\text { No. }\end{array}$} & \multicolumn{13}{|c|}{ Colorimetric data of silk and its mixed fabric } \\
\hline & \multirow[t]{2}{*}{ Dyes } & \multicolumn{6}{|c|}{$100 \%$ Silk } & \multicolumn{6}{|c|}{$50 \%$ Silk+ (25\% polyester and $25 \%$ lyocell $)$} \\
\hline & & $\mathbf{L}^{*}$ & a* & $\mathbf{b}^{*}$ & C & $\mathbf{h}^{\circ}$ & $\mathbf{K} / \mathbf{S}$ & $\mathbf{L}^{*}$ & $\mathbf{a}^{*}$ & $\mathbf{b}^{*}$ & $\mathbf{C}$ & $\mathbf{h}^{\circ}$ & $\mathbf{K} / \mathbf{S}$ \\
\hline 1 & Indigo & 26.20 & -6.06 & -14.41 & 23.10 & 262 & 14.01 & 37.91 & -6.15 & -15.30 & 21.62 & 251 & 14.60 \\
\hline 2 & Kum kum & 27.71 & -5.84 & -15.95 & 23.51 & 251 & 13.70 & 31.04 & -5.98 & -15.52 & 22.02 & 255 & 14.50 \\
\hline 3 & Barberry & 29.54 & -5.96 & -14.24 & 22.95 & 262 & 13.95 & 32.06 & -5.30 & -15.08 & 21.59 & 251 & 14.54 \\
\hline 4 & $\begin{array}{l}\text { Reactive } \\
\text { Dye (M) }\end{array}$ & 36.80 & -4.65 & -16.84 & 23.01 & 256 & 14.30 & 27.42 & -5.30 & -14.87 & 22.14 & 265 & 14.84 \\
\hline 4 & $\begin{array}{l}\text { Reactive } \\
\text { Dye }(\mathrm{H})\end{array}$ & 36.50 & -6.95 & -16.62 & 22.87 & 253 & 14.42 & 35.26 & -4.32 & -15.15 & 23.54 & 241 & 14.87 \\
\hline 6 & $\begin{array}{l}\text { Sulphur } \\
\text { Dye }\end{array}$ & 28.65 & -4.75 & -16.16 & 23.54 & 246 & 14.21 & 33.32 & -4.62 & -15.18 & 23.95 & 268 & 14.65 \\
\hline \multicolumn{7}{|c|}{ Mean } & 14.1 & \multicolumn{5}{|c|}{ Mean } & 14.67 \\
\hline \multicolumn{7}{|c|}{ Standard Deviation } & $\begin{array}{l}0.262 \\
7\end{array}$ & \multicolumn{5}{|c|}{ Standard Deviation } & $\begin{array}{l}0.154 \\
9\end{array}$ \\
\hline \multicolumn{7}{|c|}{ Variance } & $\begin{array}{l}0.069 \\
0\end{array}$ & \multicolumn{5}{|c|}{ Variance } & 0.024 \\
\hline
\end{tabular}

\subsection{Fastness properties of dyed silk and its mixed fabric}

The fastness properties (wash, light and rubbing) of natural (indigo, kum kum and barberry) and synthetic (reactive dye (M), reactive dye $(\mathrm{H})$ and sulphur) dyes applied on silk and its mixed fabric are given in Table 8.

Table 8: Fastness properties of dyed silk and its mixed fabric dyed with natural and synthetic dyes.

\begin{tabular}{|c|c|c|c|c|c|c|c|c|c|}
\hline \multirow{4}{*}{$\begin{array}{c}\text { S. } \\
\text { No. }\end{array}$} & \multirow{4}{*}{ Dyes } & \multicolumn{8}{|c|}{ Fastness properties of reactive dyed silk and its mixed fabric } \\
\hline & & \multicolumn{4}{|c|}{$100 \%$ Silk } & \multicolumn{4}{|c|}{$50 \%$ Silk+ (25\% polyester and $25 \%$ lyocell $)$} \\
\hline & & \multirow{2}{*}{ Wash } & \multirow{2}{*}{ Light } & \multicolumn{2}{|c|}{ Rubbing } & \multirow{2}{*}{ Wash } & \multirow{2}{*}{ Light } & \multicolumn{2}{|c|}{ Rubbing } \\
\hline & & & & Dry & Wet & & & Dry & Wet \\
\hline 1 & Indigo & 4 & 4 & 2 & $1-2$ & 4 & 4 & 2 & $1-2$ \\
\hline 2 & Kum kum & 3 & 3 & 3 & $1-2$ & $3-4$ & $2-3$ & $2-3$ & 1 \\
\hline 3 & Barberry & 3 & 3 & $2-3$ & $1-2$ & 3 & 3 & $2-3$ & $1-2$ \\
\hline 4 & Reactive Dye (M) & $3-4$ & $3-4$ & 3 & 2 & 3 & $3-4$ & $2-3$ & $1-2$ \\
\hline 5 & Reactive Dye (H) & $3-4$ & $3-4$ & 3 & $1-2$ & $3-4$ & $3-4$ & $2-3$ & $1-2$ \\
\hline 6 & Sulphur Dye & 4 & 4 & 2 & $1-2$ & 4 & 4 & 2 & $1-2$ \\
\hline & Mean & $3-4$ & $3-4$ & $2-3$ & $1-2$ & $3-4$ & $3-4$ & $2-3$ & $1-2$ \\
\hline & ndard Deviation & 0.4472 & 0.4472 & 0.4916 & 0.2041 & 0.4472 & 0.5845 & 0.2582 & 0.2041 \\
\hline & Variance & 0.2 & 0.2 & 0.2417 & 0.0417 & 0.2 & 0.3417 & 0.0667 & 0.0417 \\
\hline
\end{tabular}

\subsection{Antimicrobial property of dyed silk and its mixed fabric}

The data of antibacterial property of silk and its mixed fabris dyed with indigo, kum kum, barberry, reactive dye $(\mathrm{M})$, reactive dye $(\mathrm{H})$ and sulphur dye for Staphylococcus aureus and Escherichia coli are given in Table 9. 
Table 9: Antimicrobial property of dyed silk and its mixed fabric

\begin{tabular}{|c|c|c|c|c|c|}
\hline \multirow{3}{*}{ S.No. } & \multirow{3}{*}{ Dyes } & \multicolumn{4}{|c|}{ Antibacterial activity (Zone of Bacteriostasis - mm) } \\
\hline & & \multicolumn{2}{|c|}{ Staphylococcus aureus } & \multicolumn{2}{|r|}{ Escherichia coli } \\
\hline & & $\begin{array}{c}100 \% \\
\text { Silk }\end{array}$ & $\begin{array}{c}50 \% \text { Silk+ }(25 \% \text { polyester } \\
\text { and } 25 \% \text { lyocell })\end{array}$ & $\begin{array}{c}100 \% \\
\text { Silk }\end{array}$ & $\begin{array}{c}50 \% \text { Silk+ }(25 \% \text { polyester } \\
\text { and } 25 \% \text { lyocell })\end{array}$ \\
\hline 1 & Indigo & 39 & 42 & 36 & 38 \\
\hline 2 & Kum kum & 36 & 40 & 33 & 36 \\
\hline 3 & Barberry & 36 & 39 & 33 & 35 \\
\hline 4 & Reactive dye (M) & 37 & 42 & 34 & 37 \\
\hline 5 & Reactive dye $(\mathrm{H})$ & 38 & 42 & 35 & 38 \\
\hline 6 & Sulphur dye & 39 & 43 & 36 & 39 \\
\hline & Mean & 37.5 & 41.33 & 34.5 & 37.17 \\
\hline & Idard Deviation & 1.38 & 1.51 & 1.38 & 1.47 \\
\hline & Variance & 1.9 & 2.27 & 1.9 & 2.17 \\
\hline
\end{tabular}

\section{DISCUSSIONS}

\subsection{Absorbency of silk and its mixed fabric}

From Table 2 it is observed that there is a good absorbency in both the type of fabrics, however the mixed fabrics completes the absorption in less time. The reactive dyed $(\mathrm{H})$ materials show the maximum absorbency followed by reactive dyed (M), kum kum dyed, barberry dyed, indigo dyed, and sulphur dyed textiles. Though the mixed fabric contains polyester which is known for its high hydrophobic character, the absorption behaviour is still high compared with the $100 \%$ silk fabric. The presence of lyocell increases the absorption behaviour of the mixed fabric, as lyocell is highly hydrophilic $[10,11]$ contrast to the hydrophobic polyester. The absorbency character of lyocell is similar to that of cotton due to their presence of cellulosic polymer throughout the fiber arrangement. From the Table 2 it is seen that the mixed fabric fulfills the absorption behaviour in nearly $50 \%$ of reduced time compared to that of $100 \%$ silk fabric. The textile materials (silk and its mixed fabric) dyed with soluble dyes (both natural (kum kum and barberry) and synthetic (Reactive H \& M) ) show more absorbency than that of insoluble dyes (Indigo and Sulphur).

\subsection{Water retention in silk and its mixed fabric}

Table 3 reveals that the water retention behaviour is due to the presence of hydrophilic groups present in the polymers of the selected fabrics. The amount of water retained by a fiber mass increases with an increase in the hydrophilic tendency of the fiber. In the mixed fabric, in addition to silk, the fabric also has the presence of lyocell fiber which enhances the water attraction thereby leading for more water retention in the material.

From the Table 3, it is observed that the mixed fabric gives nearly $10 \%$ more water retention values compared with the $100 \%$ silk fabric. The reactive dyed $(\mathrm{H})$ materials show the maximum water retency followed by reactive dyed (M), kum kum dyed, barberry dyed, indigo dyed, and sulphur dyed textiles. The increased water retention values in the mixed fabrics is due to the presence of lyocell which increases the absorption behaviour of the mixed fabric, as lyocell is highly hydrophilic [10, 11].

\subsection{Wicking behaviour of silk and its mixed fabric}

Table 4 shows that the wicking values are good in both the type of fabrics, however the mixed fabrics show the more wicking behaviour compared to the $100 \%$ silk fabric. The reactive dyed $(\mathrm{H})$ materials show the maximum wicking followed by reactive dyed (M), kum kum dyed, barberry dyed, indigo dyed, and sulphur dyed textiles. This trend is common in both $100 \%$ silk and its mixed [silk (warp), polyester \& lyocell (weft - 50: 50)] fabrics. The wicking character is more for these materials dyed with soluble dyes (both natural (kum kum and barberry) and synthetic (Reactive H \& M) ) than that of insoluble dyes (Indigo and Sulphur). Wicking is the ability of a liquid to flow in narrow spaces without the assistance of external forces like gravity. As the mixed fabric contains lyocell with good absorbency behaviour, the wicking is also increased correspondingly.

The wicking behaviour of mixed fabric is nearly $15 \%$ more than that of the $100 \%$ silk fabric. This may be due to the presence of attractive groups present in lyocell polymers of mixed fabric. 


\subsection{Water vapour permeability of silk and its mixed fabric}

From the Table 5 it is clearly seen that the silk and its mixed fabric dyed with indigo, kum kum, barberry, reactive dye $(\mathrm{M})$, reactive dye $(\mathrm{H})$ and sulphur dye give good values of water vapour permeability. However, the silk mixed fabric gives high values than the $100 \%$ silk fabric due to the presence of good hydrophilic lyocell material. The water vapour permeability is due to the property of a material which permits the passage of water vapour through it, and the time rate of water vapour transmission through a unit area of flat materials of unit thickness induced by a unit vapor pressure difference between two specific surfaces under specified temperature and humidity conditions.

\subsection{Air Permeabilityof silk and its mixed fabric}

It is seen from the Table 6 that the silk mixed fabric dyed with indigo, kum kum, barberry, reactive dye (M), reactive dye $(\mathrm{H})$ and sulphur dye gives excellent air permeability behaviour compared with the corresponding $100 \%$ silk fabric. The average air permeability value of silk mixed fabric is 109.3 while that for silk fabric is 55.0 only. There is nearly a one fold increase in the air permeability value of silk mixed fabric compared with that of $100 \%$ silk fabric. This increase may be due to the physical structure of plain fabrics (as shown in Table 1) that the mixied fabric has more picks / inch than 100\% silk fabric (68 versus 60). Thus the mixed fabric has a larger number of interstices between the weft yarns than that of the $100 \%$ silk fabric. This may allow a greater air flow into this fabric.

\subsection{K/S values of dyed silk and its mixed fabric}

It is seen from Table 7 that the silk and its mixed fabric dyed with indigo, kum kum, barberry, reactive dye $(\mathrm{M})$, reactive dye $(\mathrm{H})$ and sulphur dye show good colour values. The final K/S vlaues are in accordance to the color corodinates of CIELab and CIELch. The average K/S value for the silk mixed fabric dyed with indigo, kum kum, barberry, reactive dye $(\mathrm{M})$, reactive dye $(\mathrm{H})$ and sulphur dye is 14.67 whereas this value is less for $100 \%$ silk fabric (around 14.1). The $\mathrm{k} / \mathrm{s}$ value on silk mixed fabrics for reactive dyes (M \& H) is around 14.85 followed by 14.65 (sulphur dye), 14.60 (Indigo), 14.54 (barberry), and 14.50 (kum kum) respectively. The $100 \%$ silk fabric also follows the same trend of colorimetric data, such as, for reactive dyes (M \&H) around 14.36 followed by 14.21 (sulphur dye), 14.01(Indigo), 13.95 (barberry), and 13.70 (kum kum) respectively.

From this table it is seen that both the type of fabrics show good values indicating good dyeing. The difference in the $\mathrm{k} / \mathrm{s}$ values between the two type of fabrics is only marginal. The reason for good dyeing and $\mathrm{k} / \mathrm{s}$ values is being the reaction between the reactive dye and reactive site of the polymers in the fabric materials. The silk polymer contains multiple functional groups like $-\mathrm{OH},-\mathrm{SO}_{3} \mathrm{H},-\mathrm{COOH},-\mathrm{C}_{6} \mathrm{H}_{5} \mathrm{OH},-\mathrm{NH}_{2}$. Likewise in lyocell the reactive group $-\mathrm{OH}$ is present throughout the polymeric chain. These reactive groups are responsible for the good dyeing and $\mathrm{k} / \mathrm{s}$ values in silk and silk mixed fabrics. The $\mathrm{k} / \mathrm{s}$ value around 12 and more than 12 is considered to be good colour strength. Hence, the colorimetric data on $100 \%$ silk and its mixed fabrics dyed using indigo, kum kum, bar berry, reactive dye (M), reactive dye $(\mathrm{H})$ and sulphur dye are in the accepted value.

\subsection{Fastness properties of dyed silk and its mixed fabric}

The wash fastness of the dyed silk materials is good as compared with other fatnesses like light and rubbing fastness properties as revealed in Table 8. The good wash fastness property is due to the strong reaction between the reactive groups of the polymer in the fabric materials and also of the dye. It is obvious that the light fastness and rubbing fastness properties are moderately less considered to wash fastness property due to their behaviour towards these applications.

\subsection{Antimicrobial property of dyed silk and its mixed fabric}

The antimicrobial activity of the silk and its mixed fabric dyed with indigo, kum kum, barberry, reactive dye $(\mathrm{M})$, reactive dye $(\mathrm{H})$ and sulphur dye was assessed by qualitative test method. All these dyed samples showed a higher zone of inhibition against Staphylococcus aureus when compared to Escherichia coli as seen in Table 9. In general, the silk mixed fabric shows a higher zone of inhibition (both by Staphylococcus aureus and Escherichia coli) over $100 \%$ silk fabric. The sulphur dye shows maximum inhibition followed by reactive $(\mathrm{H})$ \& reactive $(\mathrm{M})$ dyes respectively in synthetic dye category whereas indigo gives maximum inhibition followed by kum kum and barberry in the natural dye category on these fabrics exhibited by staphylococcus aureus and escherichia coli. 


\section{CONCLUSIONS}

From this research work on $100 \%$ silk and silk mixed fabric dyed with natural dyes (indigo, kum kum \& barberry) and synthetic dyes (reactive (M), reactive (H) \& sulphur), the following conclusions are arrived;

The absorbency is good in both the $100 \%$ silk fabric and silk mixed fabric. However the mixed fabric gives increased absorption than the $100 \%$ silk fabric. The water retention character is more in the silk mixed fabric than the $100 \%$ silk fabric. As the absorption and water retention behaviour are more, obviously the wicking value is also good in both the type of fabrics, however the mixed fabrics show more wicking behaviour compared to the $100 \%$ silk fabric. The silk and its mixed fabric give good values of water vapour permeability and air permeability. However due to the presence of lyocell in the mixed fabric which facilitates the increase of these behaviors. The $\mathrm{k} / \mathrm{s}$ values and the fastness properties (wash, light and rubbing) are mostly similar in both the $100 \%$ silk fabric and silk mixed fabric. The overall fastness property is more for washing compared with the corresponding light and rubbing. The antimicrobial character of silk mixed fabric dyed with both natural dye (indigo, kum kum \& barberry) and synthetic dye (reactive ( $\mathrm{M} \& \mathrm{H}$ ) and sulphur) is good when compared with the corresponding $100 \%$ silk fabric.

\section{ACKNOWLEDGEMENTS}

The authors wish to thank the Management and Principal, PSG College of Technology, Coimbatore for given the permission and providing the necessary infrastructure. The authors also thank The Head, Department of Applied Science; and Head, Department of Fashion Technology, PSG CT for the kind help rendered in the completion of this work. Thanks are also due to The Under Secretary (FD - III), University Grants Commission, New Delhi 110002 for sanctioning the project (Lr. No. : 39-783/2010 (SR), Dt.: 07.01.2011).

\section{BIBLIOGRAPHY}

[1] HOJO, N., "Structure of Silk Yarn - part B": Chemical structure and processing of silk yarn, Science Publishers, Inc, Enfield, USA, pp. 135-157, 2000

[2] SHEIKH, M.R.K., FAROUQUI, F.I., MODAK, P.R., et al., "Dyeing of Rajshahi silk with basic dyes: Effect of modification on dyeing Properties", Journal of the Textile Institute, v. 97, n.4, pp. 295-300, 2006

[3] AGARWAL, D., SEN, K., GULRAJANI, M.L., "Dyeing of silk with bifunctional reactive dyes: The relationship between exhaustion and fixation”, Journal of the Society of Dyers and Colourists, v. 113, n. 5-6, pp. 174-178, 1997

[4] ZUWANG, W., "Recent developments of reactive dyes and reactive dyeing of silk”, Review of Progress in Coloration and Related Topics, v. 28, n. 1, pp. 32-38, 1998

[5] OSMAN, E.M., MICHAEL, M.N., GOHAR, H., "The Effect of Both UVIOzone and Chitosan on Natural Fabrics”, International Journal of Chemistry, v. 2, n. 2, pp. 28-39, 2010

[6] IRIYAMA, Y., MOCHIZUKI, T., et al., "Plasma treatment of silk Fabrics for better dyeability", Journal of Photopolymer Science and Technology, v. 15, n. 2, pp. 299-306, 2002

[7] KHANCHAIYAPOOM, K., PRACHAYAWARAKORN, J.,"Physical and Dyeing Properties Using Natural Dyes of Degummed Silks (Bombyx mori)Graftedby2-Hydroxyethyl Methacrylate”, Journal of Metals, Materials and Minerals, v. 18, n. 2, pp. 237-240, 2008

[8] PRACHAYAWARAKORN, J., KHANCHAIYAPOOM, K., "Dyeing Properties of Bombyx mori Silks Grafted by 2-Hydroxyethyl Methacrylate (HEMA)”, Fibers and Polymers, v. 11, n. 5, pp. 1010-1017, 2010

[9] ALBRECHT, W., REINTJES, M., WULFHORST, B., "Lyocell fibers”, Chemical Fibers International, v. 47, n. 5, pp. 298-304, 1997

[10] COLOM, X., CARRILLO, F., "Crystallinity changes in lyocell and viscose-type fibers by caustic treatment”, European Polymer Journal, v. 38, n. 11, pp. 2225-2230, 2002

[11] SIROKY, J., BLACKBURN, R.S., BECHTOLD, T., et al., "Attenuated total reflectance Fouriertransform Infrared spectroscopy analysis of crystallinity changes in lyocell following continuous treatment with sodium hydroxide",Cellulose, v. 17, n. 1, pp. 103-115, 2010

[12] RAO, M.V.S., TALELE, A.B., A Guide to Crimping/Texturing Technology, MANTRA, Man Made Textiles Research Association, Surat, India, 1992 
[13] ALISH-MARK, M., HERRMANN, A., ZIMMERMANN, W., "Increase of the hydrophilicity of polyethylene terephthalate fibers by hydrolases from Thermomonospora fusca and Fusarium solani f. sp. Pisi”, Biotechnology Letters, v. 28, n. 10, pp. 681-685, 2006

[14] BAL, S., BEHERA, R.C., "Structural investigation of chemical treated polyester fibers using SAXS and other techniques”, Journal of Minerals and Materials Characterization and Engineering, v. 5, n. 2, pp. 179198, 2006

[15] GULRAJANI, M.L., GUPTA, D., Natural Dyes and their Application to Textiles, Indian Institute of Technology Delhi Publication, New Delhi, 1992

[16] TROTMAN, E.R., Dyeing and Chemical Technology of Textile Fibers, 6th edition, Edward Arnold, London, 1984

[17] SHENAI, V.A., Technology of Dyeing, Sevak Publications, Mumbai, India, 1977

[18] AATCC Test Method 79-2010, Absorbency of Textiles, Technical Manual of the AATCC, American Association of Textile Chemists and Colorists, Research Triangle Park, USA, 2010

[19] AATCC Test Method 21-1978, Static Absorption Test, Technical Manual of the AATCC, American Association of Textile Chemists and Colorists, Research Triangle Park, USA, 1979

[20] TYAGI, G.K., KRISHNA, G., et al., “Comfort aspects of finished polyester-cotton and polyester-viscose ring and MJS yarn fabrics”, Indian Journal of Fiber \& Textile Research, v. 34, n. 2, pp. 137-143, 2009

[21] SWARNA, N., JEYAKODI MOSES, J., "Surface Modification of Polyester Fabric using Polyvinyl Alcohol in Alkaline Medium”, Indian Journal of Fiber \& Textile Research, v. 37, n. 3, pp. 287-291, 2012

[22] ASTM - E96, Standard Test Methods for Water Vapor Transmission of Materials, ASTM International, West Conshohocken, USA, 2000

[23] ASTM - D737, Standard Test Methods for Air Permeability of Textile Fabrics, ASTM International, West Conshohocken, USA, 2012

[24] PETERS, R.H., The Physical Chemistry of Dyeing, Textile Chemistry, Elsevier Scientific Publications Company, Amsterdam, 1975

[25] BIS Test Method IS:764-1979, Test 3, Indian Standard Method for Determination of Colour Fastness of Textile Materials to Washing, Bureau of Indian Standards, 1979

[26] AATCC Test Method 16E-2004, Colour Fastness to Light, Technical Manual of the AATCC, Research Triangle Park, U.S.A, 2004

[27] AATCC Test Method 8-2007, Colour Fastness to Crocking, Technical Manual of the AATCC, Research Triangle Park, U.S.A, 2007

[28] AATCC Test Method 147-2004. Antibacterial Activity Assessment of Textile Materials-Parallel Streak Method, Technical Manual of the AATCC, Research Triangle Park, USA, 2004 


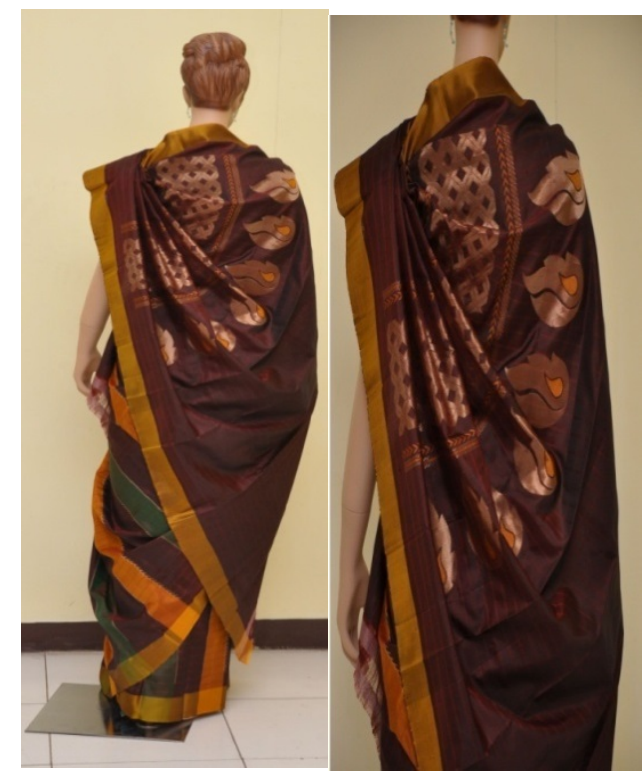

Plate -I): View of the commercially produced $100 \%$ Silk fabric

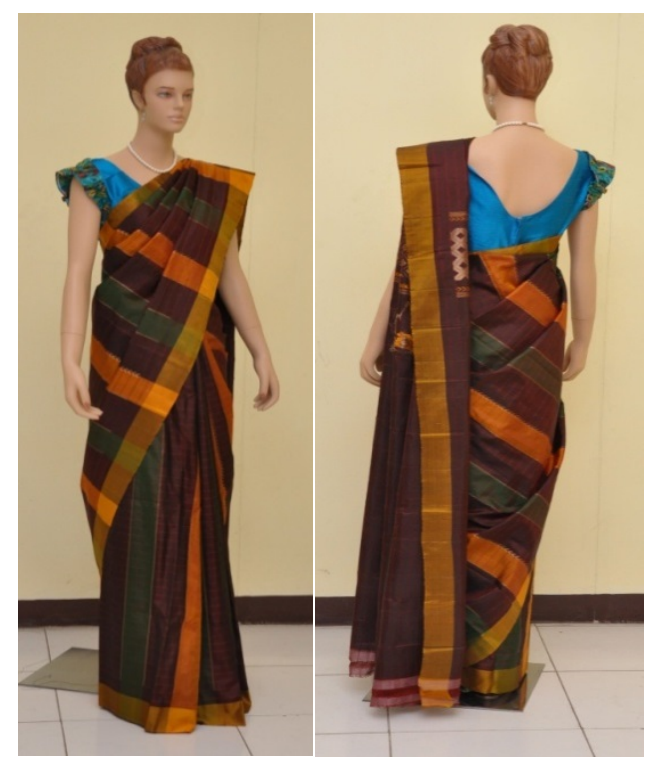

Plate -II): View of the commercially produced Silk mixed (Polyester \& Lyocell) fabric 